\title{
Drug Prices Under the Medicare Drug Discount Card Program
}

\author{
Emin M. Dinlersoz, Rubén Hernández-Murillo, Han Li, and Roger Sherman
}

\begin{abstract}
In early 2004, the U.S. government initiated the Medicare Drug Discount Card Program (MDDCP), which allowed card subscribers to obtain discounts on prescription drugs. Pharmacy-level prices were posted on the program website weekly with the hope of promoting competition among card sponsors by facilitating consumer access to prices. A large panel of pharmacy-level price data collected from this website indicates that price dispersion across cards persisted throughout the program. Prices declined initially when consumers were choosing cards, but rose later when subscribers were restricted to commit to their card choices. In contrast, contemporaneous prices from online drug retailers, which were unrelated to the program, rose steadily over time, indicating that program prices evolved in a way different from the general evolution of prices outside the program. (JEL D43, D83, I11, I18, L11, L13, L50)
\end{abstract}

Federal Reserve Bank of St. Louis Review, November/December 2008, 90(6), pp. 643-66.

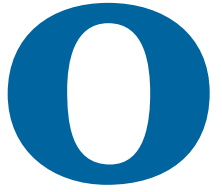

n April 29, 2004, in conjunction with the Medicare Drug Discount Card Program and Transitional Assistance Program (MDDCP), the U.S. government activated a website to publicize prices offered by discount cards for more than 800 prescription drugs at individual pharmacy levels across all zip code areas in the United States. The MDDCP was initiated as a transition to the broader Medicare Part D prescription drug assistance program that took effect in January 2006, aiming to lower the cost of drugs and therapy for elderly and handicapped individuals covered by Medicare. The price information on the MDDCP website was updated on a weekly basis for the duration of the program. This mandatory release of prices continues under the Medicare Part D program, and it is unmatched in scale in the history of government policy on information transparency.

The MDDCP and its successor program, Medicare Part D, were intended to induce competition among drug card sponsors, largely through the extensive amount of price information that drug card sponsors were required to release on the website. The premise was that the ease of consumer search for prices in the program website would enable them to choose the lowest-price card sponsor, leading to intensified competition among sponsors. However, at the same time that the MDDCP generated price information with the intent to boost competition among drug cards, the program design also required subscribers to commit to a single drug card once they subscribed, rather than being allowed to switch cards at will. This institutional constraint on consumer switching, among other factors, could inhibit competi-

Emin M. Dinlersoz is a senior economist at Cornerstone Research, Washington, DC. Rubén Hernández-Murillo is a senior economist at the Federal Reserve Bank of St. Louis. Han Li is an associate professor at the Research Institute of Economics and Management, Southwestern University of Finance and Economics, Chengdu, Sichuan, China. Roger Sherman is professor emeritus, Department of Economics, University of Houston.

(C) 2008, The Federal Reserve Bank of St. Louis. The views expressed in this article are those of the author(s) and do not necessarily reflect the views of Cornerstone Research, the Federal Reserve System, the Board of Governors, or the regional Federal Reserve Banks. Articles may be reprinted, reproduced, published, distributed, displayed, and transmitted in their entirety if copyright notice, author name(s), and full citation are included. Abstracts, synopses, and other derivative works may be made only with prior written permission of the Federal Reserve Bank of St. Louis. 
tion by preventing consumers from switching to low-price providers. Thus, a major question is whether MDDCP competition among the drug card sponsors was indeed effective in lowering drug prices as intended by the program initiators.

This paper studies the dynamics of prices over the course of the program by using a large sample of prices collected from the MDDCP website for several weeks. The empirical analysis indicates that the program resulted in economically significant and persistent price dispersion across cards. More importantly, the evidence points to a nonmonotonic time path for prices. Drug prices declined in the early phases of the program when card subscription was still diffusing across consumers, and they rose later when new card subscriptions slowed and consumers could no longer switch cards, although the magnitudes of these shifting trends were not exceptionally large relative to the overall average of program prices. As a benchmark for comparison, contemporaneous prices unrelated to the program were collected from online drug retailers, and these prices exhibited a steady upward trend. In particular, when MDDCP prices declined, online prices rose, and when both sets of prices rose, the rise in MDDCP prices was actually greater than the rise in online prices. Thus, MDDCP prices evolved differently from the general evolution of drug prices outside the MDDCP, indicating that the time path of prices within the MDDCP cannot be explained simply by general trends in regular online drug prices.

The analysis of the evolution of prices under the MDDCP is relevant because of the potentially large welfare consequences of government policies aimed at increasing competition, which continue under Medicare Part D. At the time of the study, the population eligible for drug cards was around 7.5 million, and it has continued to grow since Medicare Part D took effect in 2006. The design of a viable prescription drug program for the elderly is still a major policy issue and the success of the ongoing Medicare Part D remains to be seen. Therefore, lessons learned from the MDDCP experience are valuable in assessing the success of government-sponsored competition and information dissemination about prices. By increasing program awareness, making the price information publicly available through its website, and helping eligible consumers choose cards, the program's goal was to increase competition among rival prescription drug suppliers and to help establish a market in which such increased competition persisted in the long run even after the broader Medicare Part D took effect. The belief, at least in part, was that effective consumer search for lower prices would discipline the pricing behavior of suppliers and lead to lower prices. Certain theories of consumer search (e.g., Stahl, 1989) suggest that easier consumer search can exert downward pressure on prices in a market. Related empirical work (notably, Brown and Goolsbee, 2002) also demonstrated that the diffusion of consumer search can be associated with lower prices, provided consumers were uninhibited in switching to lower-priced suppliers. Yet, the results here suggest that no systematic and economically significant decline in prices occurred when the overall price dynamics within the program are considered.

Official surveys and studies on the marketing performance of the MDDCP point to several reasons that appear to have prohibited effective search by consumers, which could have allowed the reallocation of consumers to lower-priced cards. ${ }^{1}$ Efforts to inform potential beneficiaries about drug cards and the enrollment process were limited, particularly about the cost of cards and the extent of the discounts available. In addition, the program's website and the existing help lines were not particularly useful in guiding consumers to choose the card that was best for them. Thus, these studies do not suggest any strong indication that consumers were able to make highly informed and close to ideal choices. Consumers also were often confused about the abundance of cards and pharmacies from which to choose, which made it difficult to make the best choice. Furthermore, the low inherent propensity of Internet usage and searching capability among elderly individuals prevented effective usage of the website for consumer decisionmaking. All these impediments

\footnotetext{
1 See, for instance, the 2005 U.S. Government Accountability Office study GAO-06-13R.
} 
seem to have led to price dynamics in the program that did not coincide with the program's intended effects.

The rest of this paper is organized as follows. The next section provides background for the MDDCP. The third section presents some theoretical guidance, followed by a description of the data. Empirical analysis and results are then described before our concluding section.

\section{THE MDDCP BACKGROUND}

The design and the institutional environment of the MDDCP are crucial for understanding the functioning of the retail drug markets created by the program. The MDDCP allowed qualified drug card sponsors to make arrangements with drug manufacturers to obtain discounts and pass these discounts on to Medicare recipients. Eligible consumers could subscribe on a strictly voluntary basis to a card of their choice and obtain their prescriptions at a discount specified by the card sponsor. Prescriptions were available either from retail pharmacies or by mail from mail-order pharmacies that had arrangements with the card sponsor. An individual consumer subscribed to a card by paying a fixed annual fee (for at most two years), ranging between $\$ 0$ and $\$ 30$, and thereafter was entitled to receive that card's discounts. The consumer's problem consisted of two stages: first, choosing a drug card that provided the best discount on the bundle of drugs used by the consumer and second, choosing a retail (or mail-order) pharmacy that sold the drugs of interest.

Certain institutional aspects of the program were relevant for the dynamics of program prices. First, a card sponsor was not required to commit to a given level of discount on drugs over time. This flexibility in card prices left the door open for price fluctuations that could result from competition among cards, above and beyond general fluctuations in drug prices such as those related to changes in manufacturers' costs or changes in demand after the introduction of a generic. For a given card, there was also no prior commitment for prices to be the same across all pharmacies that offered discounts under the card.

Second, in addition to the usual consumer search and switching costs that contribute to price dispersion in drug retail markets (see ScottMorton, 1997, and Sorensen, 2000, 2001), prohibitive consumer switching costs were inherent in the very design of the program. ${ }^{2}$ Once enrolled in a card program, a consumer was not allowed to switch to another card, except in certain special cases, such as moving to a new location or a card sponsor exiting the market. This restriction on switching introduced additional friction and inertia into the market, which may have impeded reallocation of consumers to low-price card sponsors over time. The MDDCP had a nationally coordinated switching period between November 15 and December 31, 2004, during which consumers were allowed to review their card choices and change them if they wished to do so. After this period, a consumer who was already enrolled in a card was not allowed to switch to another card until the end of the program, subject to the exceptions mentioned. The prevention of switching after the switching period and the timing of the switching period could potentially lead to price dynamics driven by the card sponsors' incentives to charge lower prices in the early stages of the program to attract subscribers, and then to increase their prices once consumers were locked in to their card choices.

Third, the diffusion of card enrollment among eligible consumers was expected to be gradual, not instantaneous. Consumers had to evaluate card choices before making a decision. One of the main criticisms of the MDDCP was the complexity of the card choice process related to the abundance of alternative plans whose benefits were hard to assess. This criticism applies equally to Medicare Part D. Available evidence indicated that the diffusion of card enrollment was indeed gradual. According to enrollment data from the Center for Medicare and Medicaid Services (CMS), about 6.4 million beneficiaries were enrolled in the drug card program as of September 2005,

\footnotetext{
2 Usual switching costs in the context of prescription drugs include consumer learning costs about the side effects of a new drug that can substitute for the consumer's existing drug and physicians' inertia in changing prescriptions because of rewards and loyalty programs offered by the manufacturer or the wholesaler of that drug.
} 
toward the end of the program. ${ }^{3}$ Roughly twothirds of participants enrolled early in the program (May through July 2004). Enrollment was much faster between May and October 2004 and reached about 6 million participants (about 80 percent of the total Medicare population) around October 2004. It rose little thereafter, essentially staying level after January 2005, when the switching period ended.

Moreover, most consumers eligible for cards were 65 years or older, not a group of particularly Internet-savvy consumers. Shortly before the program took effect, Fox (2004) estimated that 22 percent of adults aged 65 and older had access to the Internet. Of this group, an estimated 66 percent used the Internet to locate health information, implying that only about 14 percent of the relevant population used the Internet for health information searches. Thus, the overall propensity to use the Internet as a price search tool was not impressively high in the eligible population.

Further evidence of consumers' enrollment and experience with the program comes from an October 2005 report on the progress of the MDDCP program prepared by Abt Associates, Inc., on request from the CMS. ${ }^{4}$ Based on an extensive survey of card enrollees and non-enrollees, the report found that widespread awareness of the MDDCP was obtained within a few months of the program. Although a majority of respondents reported that they had more than enough information to make a choice among the cards, one quarter to half did not consider more than just one drug card. Some consumers simply took the first card available, whereas others were enrolled automatically. About 13 percent of survey participants obtained information from the Medicare website, either directly or with the help of a family member, friend, or counselor who accessed the website for them. Overall, the available evidence indicates that both the rate of learning about cards and the search rate for lower prices were rather low.

\footnotetext{
3 For more details of the enrollment patterns, see the 2005 U.S. Government Accountability Office study GAO-06-13R.

4 See Hassol et al. (2005).
}

\section{THEORETICAL CONSIDERATIONS}

Consumer search is an important source of price dispersion in retail drug markets (e.g., Sorensen, 2000, 2001). Static models of search are abundant in the literature (see, e.g., Salop and Stiglitz, 1977, Reinganum, 1979, Burdett and Judd, 1983, and Stahl, 1989). For instance, Stahl (1989) shows that as the proportion of consumers who are fully informed of prices increases, average price falls monotonically. Price dispersion exhibits nonmonotonic behavior, initially increasing for low values of the informed proportion, but decreasing for higher values. Although comparative statics from this static model can be used, as in Brown and Goolsbee (2002), to draw some conclusions for a dynamic framework, the MDDCP's institutional environment introduces further considerations for firms' and consumers' behavior over time, which call for a dynamic framework.

Given the available evidence on intensity of search discussed in the previous section, it is hard to argue that consumer search worked as effectively as in ordinary, nonprogram retail prescription drug markets. Factors in the previous section suggest that there may have been little consumer search in the market created by MDDCP, and the abundance of choices and the complexities of the program design may have inhibited search. Another major constraint of the program is that it prevented consumers from using more than one card or from changing their card choices after they subscribed, with few exceptions. The prohibitive switching cost could have induced card sponsors to lower their prices in the early stages of the program to attract consumers who had not yet chosen a card. But as more and more consumers were locked in to their choices, card sponsors would have incentives to raise prices. After the switching period, prices may be expected to rise as sponsors take advantage of consumers' inability to change cards.

This nonmonotonic time path of prices indeed arises in certain models of dynamic price competition with consumer switching costs, such as those of Klemperer (1987) and Farrell and Shapiro (1988). The MDDCP had a lifetime of less than 
two years, and cards were differentiated in many dimensions beyond just price. These main features of the program are captured nicely by the model of Klemperer (1987), which presents a two-period differentiated-products duopoly in which consumers are partially locked in by switching costs that they face in the second period. Switching costs make demand more inelastic in the second period. Prices are lower in the first period as firms compete to build a customer base that is valuable later. However, prices may be higher in both periods than they would be in a market without switching costs.

Two main considerations under the MDDCP may make the price dynamics differ from those in Klemperer (1987). First, Klemperer (1987) assumes perfect consumer information about prices, whereas the evidence discussed above suggests that many card enrollees under the MDDCP chose their drugs with imperfect information about the cards' benefits and prices. Lack of perfect information about prices would not change the competition in the second period, because the constraints on switching would prevent consumers from abandoning their firms even if they were informed of a lower price at some point. However, the intensity of competition in the first period could change. Firms could take advantage of consumers' imperfect information and not lower their prices as much as they would in the case of perfect information. Obviously, a related issue is that each card sponsor itself probably did not have good information on the general pattern of card enrollment and on imperfections in consumers' information about cards. If card sponsors believed, at least initially until firm evidence on enrollment patterns emerged, that consumers would make informed decisions, they would have incentives to lower their prices.

Second, the MDDCP's allowance for a round of card switching in the middle of the program created incentives for a potential price war by card sponsors. One implication is that, in addition to lower prices at the early phases of the program, lower prices would be expected during the switching period compared with nonswitching periods. There is no artificially introduced "switching period" in Klemperer (1987).
Other considerations, however, could prevent this predicted nonmonotonic path for prices. Given the continuing nature of the prescription drug program with Part D, card sponsors who use bait-and-switch strategies could harm their reputations. Although the MDDCP itself lasted only two years, many card sponsors continued to participate in Medicare Part D when it started in January 2006, so sponsors faced the possibility of alienating consumers because of bait-andswitch price strategies. One of the program's goals, as stated in the Medicare program-related website, was to prevent bait-and-switch behavior. However, the program did not spell out any strict guidelines as to what exactly constitutes bait-andswitch and how it would be prevented.

The discussion so far suggests that the level of program prices may not have declined steadily over time. In view of the institutional environment of the program and the predictions arising from models of dynamic competition with switching costs, it is possible to observe a nonmonotonic path for prices. Given the underlying complexities of the program design and the fact that consumer search was not exceptionally high in this market, the pattern the program prices followed is ultimately an empirical issue.

\section{DATA}

In this section we describe the drugs for which data were collected, the geographic areas covered, the timing of data collection, and the other prices obtained for control purposes.

\section{Drugs}

Prices were collected for 28 prescription drugs, which were chosen based on the following three criteria. First, all the drugs were in the top 100 drugs in claims filed by the elderly in 2001 , and in the top 200 highest-selling drugs for the elderly in 2003. This selection of relatively popular drugs ensures that each drug had sufficiently large demand. The relatively high demand for these drugs implies that the price dynamics we are seeking are likely to have been apparent and economically important. Second, half of the drugs are 


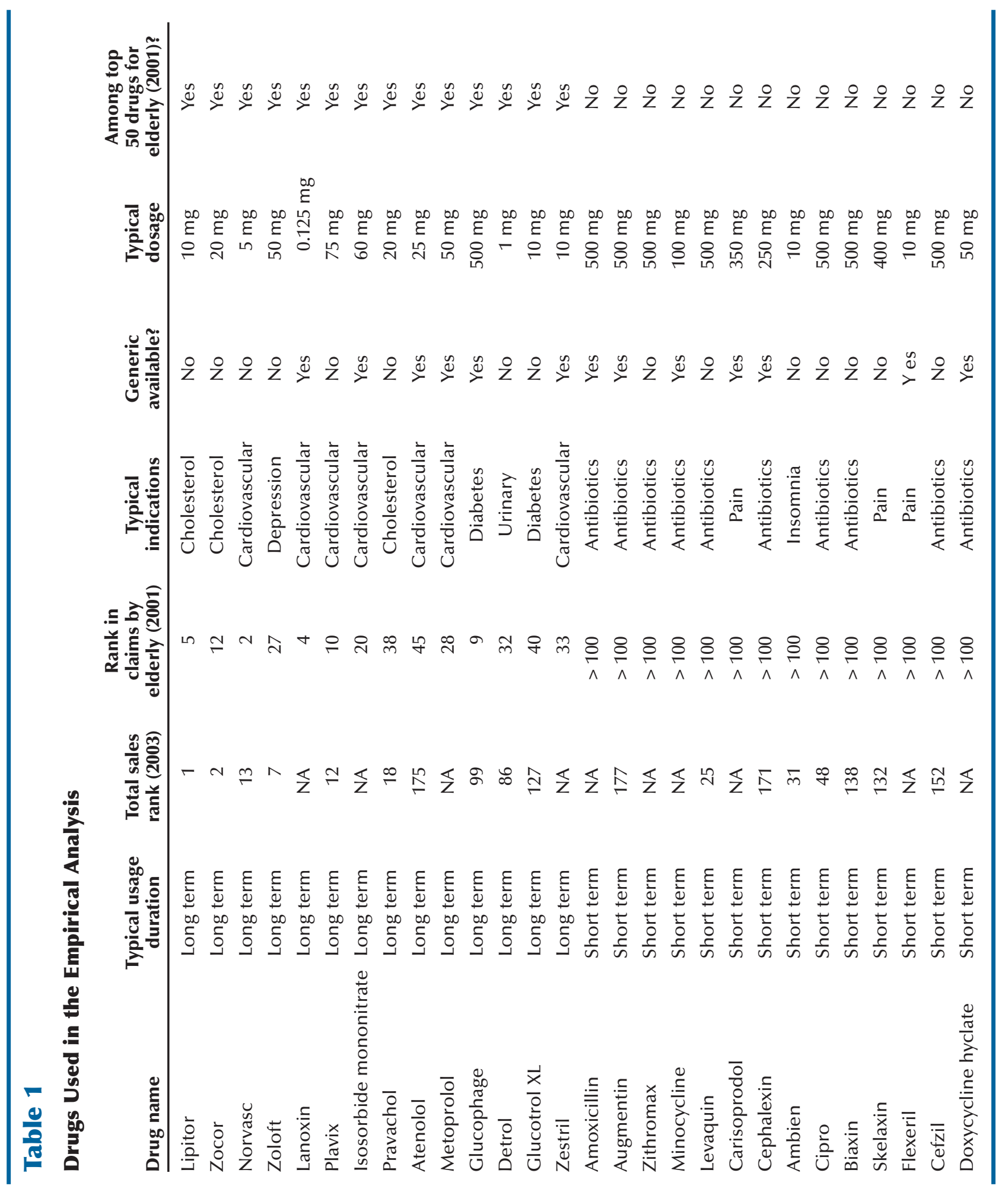




\section{Table 2}

\section{Variables Used in the Empirical Analysis}

\begin{tabular}{|c|c|}
\hline Variable & Description \\
\hline LONG_TERM & $\begin{array}{l}\text { Dummy variable, } 1 \text { if the drug is a maintenance drug, } 0 \text { if the drug is primarily for short- } \\
\text { term use }\end{array}$ \\
\hline GENERIC & $\begin{array}{l}\text { Dummy variable, } 1 \text { if the drug has a generic equivalent or is itself generic, } 0 \text { if the drug is } \\
\text { brand name }\end{array}$ \\
\hline PRES_2003 & The total number of prescriptions for a drug in 2003 \\
\hline PAT_EXPIRE & Dummy variable, 1 if the drug's patent had expired by 2004, 0 otherwise \\
\hline PAT_EXCLUSIVE & Dummy variable, 1 if the drug has an exclusive patent for a specific condition, 0 otherwise \\
\hline FDA_YEAR & The year a drug was approved by the FDA \\
\hline WALGREENS & Dummy variable, 1 if the pharmacy is a Walgreens store, 0 otherwise \\
\hline CVS & Dummy variable, 1 if the pharmacy is a CVS store, 0 otherwise \\
\hline ECKERD & Dummy variable, 1 if the pharmacy is an Eckerd store, 0 otherwise \\
\hline GEO & Dummy variable, 1 if the card offers national coverage, 0 otherwise \\
\hline FEE & The fixed one-time enrollment fee to a given card in dollars \\
\hline MFG & The number of manufacturers with which a card has a contract for discount prices \\
\hline ASSIST & Dummy variable, 1 if the card offers enrollment assistance, 0 otherwise \\
\hline MAIL & Dummy variable, 1 if the card has a mail-order option for drugs, 0 otherwise \\
\hline FORMULARY & $\begin{array}{l}\text { Dummy variable, } 1 \text { if the drug offers the entire formulary of Medicare-approved drugs, } \\
0 \text { otherwise }\end{array}$ \\
\hline FRAC65+ & Fraction of people $\geq 65$ years or older in a zip code \\
\hline MEDHINC & Median household income in a zip code \\
\hline RENT & Median rent for renter-occupied housing units in a zipcode \\
\hline FRACWHITE65+ & Fraction of people $\geq 65$ years in a zip code who are white \\
\hline FRACFEM65+ & Fraction of people $\geq 65$ years in a zip code who are female \\
\hline POP65+ & Population in a zip code $\geq 65$ years \\
\hline POPWHITE65+ & Population in a zip code $\geq 65$ years and white \\
\hline POPFEM65+ & Population in a zip code $\geq 65$ years and female \\
\hline
\end{tabular}

short-term drugs, such as antibiotics and pain killers, and the other half are long-term, maintenance drugs, such as those used for diabetes and cardiovascular diseases. The evolution of shortterm drug prices is expected to differ from that of maintenance drugs, for which consumers are likely to search more intensely for a bargain. Finally, drug dosages were selected to reflect the most frequently prescribed dosages for the drugs, so that the demand is large relative to what it would be with unusually high or low dosages. ${ }^{5}$ Each drug price pertains to a 30-day supply. The drugs and some of their attributes are presented in Table 1.

\section{Geographic Areas}

The price data from the MDDCP website were listed at the level of zip codes. Ninety zip codes were chosen by a random stratified sampling, designed to oversample zip codes with a

5 Drug-specific information was obtained from Mosby's Drug Consult $(2004,2005)$, which features information on the typical usage and dosages of drugs. 
greater proportion of the population composed of elderly residents, defined as individuals who are 65 years of age or older. To determine any demand side effects on prices, we needed to ensure a sufficient variation in market size and other demand shifters, such as income, for discount drugs. The population of residents 65 or older in a zip code is a proxy for the local market size for MDDCP cards. The proportion of elderly people in a zip code population varies in our sample from a low of 3 percent to a high of 92.6 percent; the average is 28 percent and the standard deviation is 25 percent. We also gathered zip code-level demographic data from the U.S. Census Bureau's 2000 Zip Code Statistics to analyze the price effect of demand shifters such as income and race composition (Table 2).

The program's price search engine listed prices for all pharmacies within a circle of a certain radius whose center coincides with the center of the selected zip code area. The search engine allowed for a choice of four different radii for any given zip code, and these radii varied by zip code. For densely populated urban areas, radii tended to be much smaller, whereas for less densely populated suburban and rural areas, the radii were larger, so that cardholders in these areas could obtain price information for a sufficient number of pharmacies. We collected price data for all pharmacies within the smallest and the secondsmallest radii around a given zip code. This selection enabled us to assess the sensitivity of our results to the choice of radius.

\section{Timing of Data Collection}

The price data were updated weekly on the Medicare website between April 29, 2004, and December 31, 2005. As shown in Figure 1, the sample in this paper was collected for several weeks to cover important periods when the MDDCP was in effect. ${ }^{6}$ Prices were first made available online on April 29, 2004, card enrollment began on May 3, 2004, and cards went into effect on June 1, 2004. Data collection was initiated

6 The data collection process was automated using iOpus Internet Macros software that allowed periodic recording of the data from the Medicare website. on June 21,2004 , three weeks after subscribers were first allowed to use their cards under the program. ${ }^{7}$

The first wave of data was collected each week for a period of seven weeks during the summer of 2004. We refer to this period as the preswitching period. The second wave was collected during the last week of December 2004. This week is within the period between November 15 and December 31, which was the nationally coordinated switching period. Price observations from this period enable us to test whether card sponsors lowered their prices in an effort to induce switches. Finally, the third wave was collected after the end of the switching period to assess the behavior of prices when switching cards was not allowed. We label this period the postswitching period. During the postswitching period, the collection process took place over nine collection cycles, which included data from March 7, 2005, through August 15, 2005.

Each price observation pertains to a drug sold by a pharmacy at a given location under the discount offered by a given card at one point in time. The prices are posted prices, not necessarily transaction prices. Transactions may have taken place at only a subset of the posted prices, and some cards may have had little or no sales for some drugs. Therefore, posted prices do not necessarily coincide with the set of prices at which transactions take place. Lacking sales data, we are unable to make any statements on these issues. No card sponsor imposed explicit restrictions on the geographic or time variation in prices. ${ }^{8} \mathrm{Geo}-$ graphic variation may have occurred for several reasons, including the changing demand and cost conditions or simply the changing composition of cards across locations.

\footnotetext{
7 The price data during the initial weeks of the program contained certain glitches, as noted by others (see Antos and Pinell, 2004). Some prices reported by pharmacies were found to be inaccurate and incorrect. However, these problems were fixed to a large extent within the first few weeks of the program. To ensure reliable data, we started collection in the fourth week after the cards went into effect.

${ }^{8}$ A brochure offered by a Walgreens store in Houston, Texas, specifically stated that prices were subject to change from store to store and over time.
} 
Dinlersoz, Hernández-Murillo, Li, Sherman

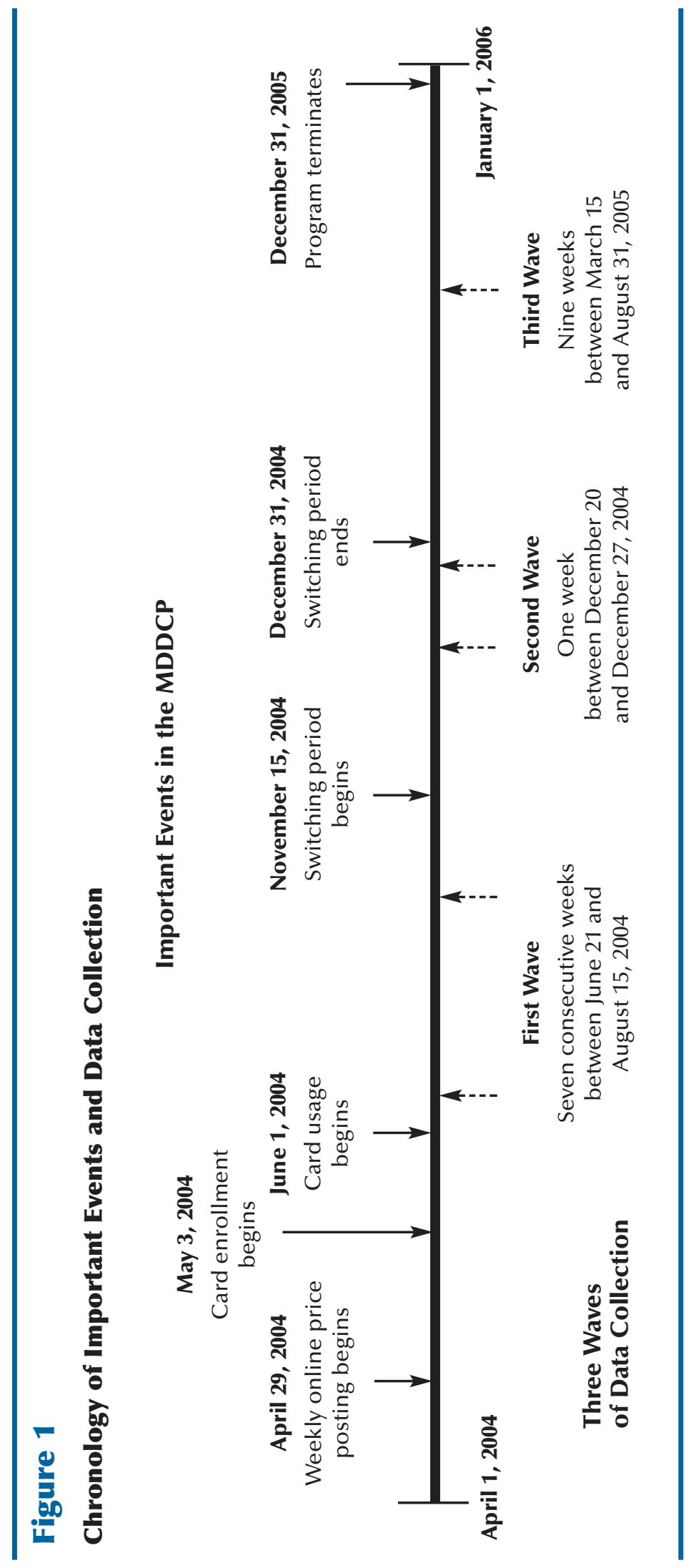




\section{Other Price Data}

Part of our analysis aims to assess the magnitude of savings offered through card usage by controlling for changes in the general level of drug prices unrelated to the MDDCP. Ideal control data for this purpose would be comparable pharmacylevel, nonprogram retail price data collected at a weekly frequency to match the sample of MDDCP prices. Unfortunately, such detailed data are difficult to find. Instead, we collected nationwide wholesale prices for the drugs in our sample. The prices listed here are from Mosby's Drug Consult (2004, 2005), which provides prices for major drug wholesalers by dosage and duration. They are a representative sample of the wholesale prices typically used to reimburse patients for their prescriptions. ${ }^{9}$ Unlike the card prices, however, these prices are not available by geographic units.

Rather, a single nationwide price is reported by each supplier, usually a manufacturer. In addition, the price quotes are not available at a weekly frequency. Instead, they are representative of the price levels for the year the database was formed. Despite their shortcomings, these prices are the best readily available benchmarks and can be used to approximate savings. As we will show, the MDDCP prices exhibit little or no geographic dispersion. Thus, the nationwide prices in Mosby's Drug Consult can serve as a reasonable benchmark.

To attribute the evolution of prices to program specifics, the general trends exhibited by drug prices over the course of the program also need to be eliminated. For this purpose, we collected concurrent weekly prices posted by Internet drug retailers for the same drugs and dosages as in the program data. We used a major Internet prescription drug search engine, which quoted prices from several Internet drug retailers. ${ }^{10}$

\footnotetext{
9 The nature of these prices is described in Mosby's reference book as follows: "Prices are AWP (average wholesale price), a benchmark price used for reimbursement. AWP represents what a retail pharmacist or a dispensing physician might pay for a product, without any special discounts. There are, however, many discounts already in place, so the AWP can often approximate the price that a consumer might pay. The prices listed here are not intended to serve as an up-to-date substitute for supplier price lists. The price listings give the reader a good idea of the range between the high and low prices."
}

Unlike program prices, online prices exhibit no geographic variation. Because they are subject to general nationwide trends in drug prices, they can serve as a good comparison group for the prices posted by card sponsors. The purpose of this comparison is twofold: First, it allows us to assess whether consumers would be able to obtain lower prices simply by purchasing at regular online prices available to general consumers, rather than going through the complicated process of choosing a card and hunting for lower prices. Second, and more importantly, online prices can be used to control for general changes in drug prices unrelated to the program. Drug prices can change over time because of changes in manufacturers' costs, availability of new substitute drugs, general inflation, or other factors. All such general trends are expected to apply in similar ways to MDDCP prices and online prices. Therefore, if different time patterns are observed for program prices versus other online prices, it is likely that program effects are an important cause. However, online prices may not reflect the exact set of nonprogram prices available to Medicare-eligible consumers. These consumers typically do not buy at regular online prices. Thus, online prices should not be viewed as an exact control group for Medicare-eligible consumers, but rather as a benchmark to control for general trends.

\section{ANALYSIS}

We begin with an analysis of the variation in price levels, followed by estimates of the extent of savings possible through the MDDCP. We then focus on price dynamics using the second-smallest radius for each zip code. The results were very similar when the smallest radius was used instead.

\section{Analysis of Price Variation}

The starting point of our analysis is understanding whether significant price dispersion

\footnotetext{
10 Once again, the data were collected by using iOpus Internet Macros from the website destinationrx.com. Our sample includes eight online retailers. Online stores of two major discount retailers (costco.com and walmart.com), online stores of two large drug retail chains (cvs.com and homemed.com), and the pharmacy branch of one major health care service provider (aarpharmacy.com).
} 


\section{Figure 2}

\section{Lipitor Price Dispersion: Week of June 28 to July 3, 2004}

All Prices

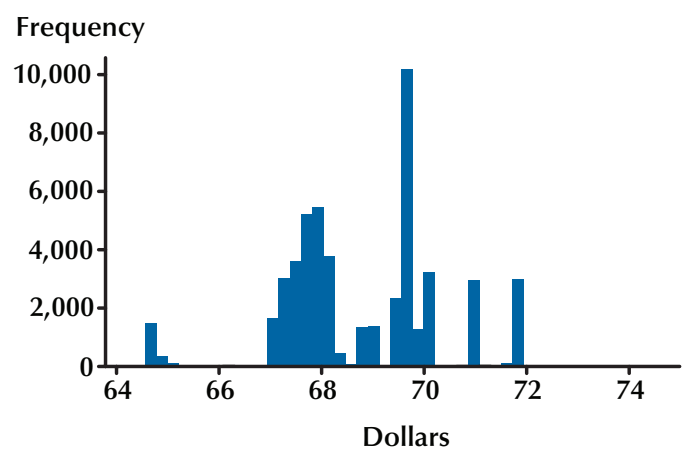

Standard Deviation within Card

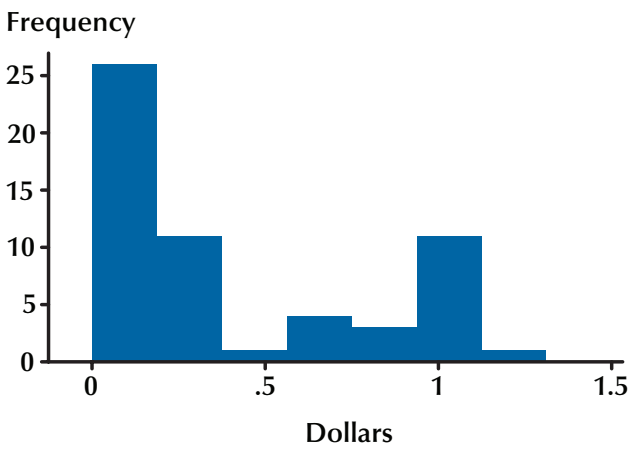

Average Prices by Card

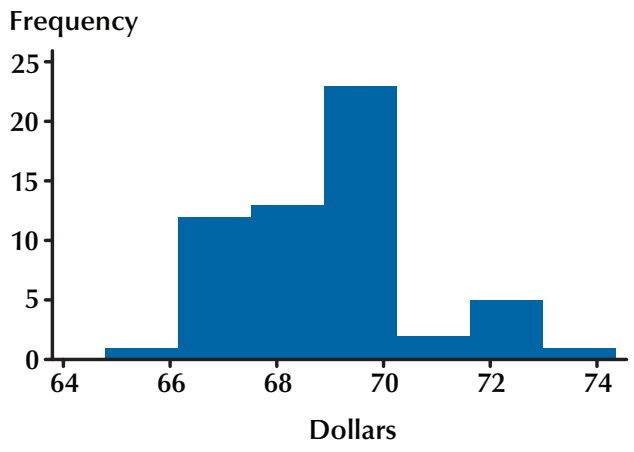

Coefficient of Variation within Card

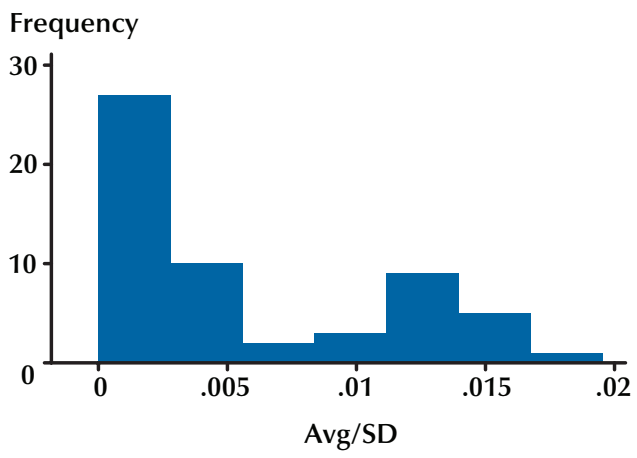

existed in the market for drug discount cards and, if so, what drove that dispersion. Figure 2 illustrates the dispersion of prices for one drug, Lipitor, for the week of June 28-July 3, 2004. The upperleft panel is the histogram of the entire set of Lipitor prices observed across cards, zip codes, and pharmacies. The upper-right panel is the distribution of the average price within a given card. The average price for a card is calculated using all price observations pertaining to the card. The average price varies between about $\$ 65$ and $\$ 74$. However, as shown in the two lower panels, the dispersion of price within a card is usually very small, amounting to an economically negligible variation across pharmacies within a card, even though such lack of variation was not explicitly guaranteed a priori by any card.
To determine whether the pattern in Figure 2 is typical of all drugs, we consider a general expression for the price $p_{d r c z t}$ of drug $d$ offered by card $c$ at pharmacy $r$ in zip code $z$ at time $t$ :

$$
p_{d r c z t}=\mu+f_{d}+f_{r}+f_{C}+f_{z}+f_{t}+e_{d r c z t},
$$

where $\mu$ is a constant, $f_{i}$ is a fixed effect for $\mathrm{i} \in$ $\{d, r, c, z, t\}$, and $e_{d r c z t}$ is a zero mean error term that accounts for remaining unobserved factors. The contribution of each of the main factors to the overall variation in price can be analyzed by using analysis of variance (ANOVA) to understand the components of variation in prices. Because pharmacies are "nested" within zip codes, a nested ANOVA was performed to decompose the total variation in prices for each drug. Results of the ANOVA for the first week of data (June 21-27, 
2004) showed that the variation in price of any drug across cards is the major component of the total variation in drug prices. On average, about 87 percent (standard deviation [SD] 15.3 percent) of the total variation in price is explained by the variation across cards, and there is little variation within cards. The variation across zip codes was only 0.5 percent (SD 2.1 percent) of the total variation on average, and the variation across pharmacies accounted, on average, for only 1.3 percent (SD 1.8 percent) of the total variation. The hypothesis that the average price of a drug is equal across cards is rejected strongly for all drugs. We repeated the ANOVA for other weeks and the findings supported the same conclusions. ${ }^{11}$

The finding of little variation in retail prices across zip codes raises the issue of how much geography affects pharmacies' pricing behavior. By the effect of geography, we mean the locationspecific factors that may affect prices, such as income level of residents, population, and age composition in a location, which are particularly relevant as demand shifters. The ability to control for all other factors is important in investigating geographic variation in prices. The ideal experiment would look at the geographic variation in prices for a given drug and card combination, holding constant the pharmacy composition across zip codes. Such an experiment is impossible, however, because pharmacy composition changes across zip codes. Nevertheless, a close approximation to this ideal experiment is possible by looking at the prices charged by the stores of a given pharmacy chain across zip codes. The individual stores of a chain, such as Walgreens or CVS, tend to have very similar structures and practices, so a good approximation can be obtained by assuming that the store-level features are roughly constant across zip codes for a given chain. We calculated the coefficient of variation of prices across all stores of a pharmacy chain for each drug and card combination. In almost all cases, the coefficient of variation was either

\footnotetext{
${ }^{11}$ We also performed the ANOVA for mail-order prices for cards with a mail-order option. Not surprisingly, the entire variation in the case of mail-order prices (excluding shipping charges) was
} attributable to the cards. exactly zero or very close to zero. Thus, price variation across zip codes arose mainly because the composition of cards and pharmacies changed across zip codes.

Although the analysis of variance in prices clearly indicates that much of the cross-sectional variation was attributable to the variation across cards, it does not provide information about specific factors responsible for this variation. Identifying key demand and supply factors that affect prices is important for understanding why prices differed across drugs, cards, pharmacies, or zip codes.

Consider the following version of equation (1) that includes explanatory variables explicitly for a given a time period (week):

$$
p_{d r c z}=\mu+\beta_{d} X_{d}+\beta_{r} X_{r}+\beta_{c} X_{c}+\beta_{z} X_{z}+\varepsilon_{d r c z},
$$

where $\beta_{i}$ is a $K_{i} \times 1$ vector of coefficients and $X_{i}$ is a $K_{i} \times N$ matrix of observables, for $i=d, r, c, z$. Each $X_{i}$ has the form

$$
\left[x_{1} X_{2} \ldots x_{K_{i}}\right]^{\prime},
$$

where $x_{j}$ is an $N \times 1$ vector that contains variables specific to cluster $j=1, \ldots, K_{i}$ within group $i=d, r, c, z$.

The structure of the error term in equation (2) is assumed to be

$$
\varepsilon_{d r c z}=\varepsilon_{d}+\varepsilon_{r}+\varepsilon_{c}+\varepsilon_{z}+e_{d r c z},
$$

where $e_{d r c z}$ is the error term in equation (1) and is assumed to be uncorrelated across observations. The error terms $\varepsilon_{i}(i \in\{r, d, c, z\})$ represent the remaining unobserved part of the fixed effect $f_{i}$ in (1) after the observable $X_{i}$ is added to the specification in equation (1) to obtain equation (2). Specification (3) implies that error terms are correlated within drugs, cards, pharmacies, and zip codes because of the presence of cluster-specific errors $\varepsilon_{i}(i \in\{r, d, c, z\})$. Because the component $\varepsilon_{i}$ is fixed within cluster $i$, we can include dummy variables for drugs, cards, pharmacies, and zip codes to account for these unobserved components. The error term defined in equation (3) then reduces to $e_{d r c z}$ as in equation (1), which is assumed to be uncorrelated across observations within a cluster, and we can implement the regres- 
Table 3

Static Price Regression

\begin{tabular}{|c|c|c|}
\hline \multirow[b]{2}{*}{ Independent variables } & \multicolumn{2}{|c|}{ Dependent variable: Price } \\
\hline & $\mathrm{I}$ & II \\
\hline LONG_TERM & $-51.10(0.04)$ & $-51.10(0.04)$ \\
\hline GENERIC & $-11.58(0.07)$ & $-11.58(0.07)$ \\
\hline PRES_2003 & -0.0000027 (0.0000001) & $-0.0000027(0.0000001)$ \\
\hline PAT_EXPIRE & $48.09(0.06)$ & $48.09(0.06)$ \\
\hline PAT_EXCLUSIVE & $192.93(0.09)$ & $192.93(0.09)$ \\
\hline FDA_YEAR & $1.89(0.02)$ & $1.89(0.02)$ \\
\hline WALMART & $0.14(0.05)$ & $0.16(0.06)$ \\
\hline CVS & $-0.94(0.06)$ & $-0.94(0.06)$ \\
\hline ECKERD & $0.69(0.03)$ & $0.68(0.04)$ \\
\hline GEO & $4.94(0.61)$ & $5.14(0.61)$ \\
\hline FEE & $0.07(0.01)$ & $0.08(0.01)$ \\
\hline MFG & $-0.44(0.06)$ & $-0.47(0.06)$ \\
\hline ASSIST & $-4.15(0.7)$ & $-4.17(0.7)$ \\
\hline MAIL & $2.04(0.48)$ & $2.13(0.48)$ \\
\hline FORMULARY & $1.82(0.15)$ & $1.73(0.17)$ \\
\hline FRAC65+ & $-0.33(0.09)$ & - \\
\hline MEDHINC & $-0.00037(0.000013)$ & $-0.00022(0.000097)$ \\
\hline RENT & $0.0064(0.00037)$ & $0.0066(0.00039)$ \\
\hline FRACWHITE65+ & $-0.29(0.03)$ & - \\
\hline FRACFEM65+ & $-0.24(0.02)$ & - \\
\hline POP65+ & - & $-0.03(0.002)$ \\
\hline POPWHITE65+ & - & $0.029(0.0017)$ \\
\hline POPFEM65+ & - & $0.0024(0.0003)$ \\
\hline Card dummies & $\mathrm{Y}$ & $\mathrm{Y}$ \\
\hline Drug dummies & $\mathrm{Y}$ & $\mathrm{Y}$ \\
\hline Zip code dummies & $\mathrm{Y}$ & $\mathrm{Y}$ \\
\hline Pharmacy dummies & $\mathrm{Y}$ & $\mathrm{Y}$ \\
\hline$N$ & $1,230,215$ & $1,230,215$ \\
\hline$R^{2}$ & 0.98 & 0.98 \\
\hline
\end{tabular}


sion in equation (2) without using any cluster effects. $^{12}$

The results of the regression are shown in Table 3 for two specifications for the week of June 21-27, 2004. We used the same specification for other time periods and the results were robust. In evaluating the results, it should be noted that the drugs in our sample form only a subset of all drugs (28 of more than 800 drugs) covered by the MDDCP. Therefore, some characteristics that would apply in general to the drugs in the entire list of the MDDCP may not be fully represented in this relatively small sample.

The explanatory variables, including the dummies, account for 98 percent of the variation in prices. Given the large number of observations, almost all coefficients are precisely estimated. Long-term maintenance drugs in our sample were, on average, cheaper than the short-term drugs, based on the prices for 30-day supplies. ${ }^{13}$ Generic drugs and brand-name drugs for which generic alternatives are available were cheaper compared with drugs that do not have generic alternatives. The prices were also lower for drugs that are prescribed more frequently. In addition, newer drugs had higher prices, as indicated by the positive coefficient on the year of approval by the FDA.

The coefficients on selected pharmacy chains suggest that Wal-Mart had slightly higher prices, by about 14 cents, than those of the omitted category of all remaining pharmacies, while CVS prices were lower by about a dollar than those of the omitted category. Eckerd, which merged with CVS in the spring of 2004 shortly before the MDDCP took effect, had prices that were higher by about 70 cents than those of the omitted category.

\footnotetext{
${ }^{12}$ Because of the large number of dummy variables in this regression (>1,000 pharmacy dummies), we use the "de-meaned" regression approach (Greene, 1993, pp. 468-69). By de-meaning the observations by pharmacy, we eliminate the pharmacy dummies and still obtain the usual ordinary least square (OLS) estimates of the coefficients of interest.

${ }^{13}$ The price difference should not be taken as evidence that the cost of therapy is lower for long-term drugs in general, because longterm prescriptions typically are renewed for several months and some short-term prescriptions are prescribed for periods shorter than a month (antibiotics such as Zithromax, which are used for intense treatment for a week in certain cases). If the drug is used only seven days, the cost of therapy will be low.
}

Cards with national coverage and with a mailorder service tended to have higher prices than cards that did not have national coverage and mail-order service. Cards with higher subscription fees and with a broader formulary also tended to have higher prices. Cards that had arrangements to provide discounts with a larger number of drug manufacturers and those that provided enrollment assistance had lower prices than the cards that did not offer these benefits. Certain quality dimensions, such as formulary breadth, extensive geographic coverage, and cost-reducing features such as association with a larger number of manufacturers, apparently were important for the differences in price across card sponsors.

Demographic characteristics of zip code areas also influenced prices to some extent. Zip codes with a higher proportion of elderly people in the population had lower prices. Zip codes with a higher median household income also had lower prices, whereas zip codes with higher housing costs were associated with higher drug prices; but these effects are relatively small.

\section{Estimates of Savings}

The finding of differences in prices across cards noted in the previous section raises the following question: Were the differences large enough to reward searching for lower prices across cards? Several small-scale studies tried to assess the extent of the discounts in the early phases of the program with only a handful of drugs and a few zip codes. ${ }^{14}$ Such investigations generally found some savings accruing to cardholders, but the small scale of these investigations prevented any general conclusions. In the following text, we ignore the card enrollment fee, which in most cases was zero and could not exceed $\$ 30$, and look only at the savings a cardholder could obtain from using the card to purchase drugs at card prices versus purchasing at regular retail or online prices.

\footnotetext{
${ }^{14}$ See, for example, Antos and Ximena (2004). Their approach first identifies a few health conditions that are common among the elderly and then calculates the total price of a bundle of drugs typically prescribed to remedy these conditions.
} 
Let $\bar{p}_{d c t}$ be the average price of drug $d$ for card $c$ in week $t$, where the average is taken across all pharmacies selling drug $d$ offered by card $c$. Define $\bar{p}_{d t}$ and $p_{d t}^{\min }$ as the average and the minimum of $\bar{p}_{d c t}$ across cards in week $t$. Similarly, define the average and minimum regular prices obtained from Mosby's (2004) database as $\bar{p}_{d}^{\text {Mosby }}$ and $p_{d}^{\text {Mosby, min }}$, where the average and the minimum are calculated across the wholesalers listed in the Mosby's database for a given drug. In addition to the prices in Mosby's database, a separate, independent source is the set of prices we collected from online pharmacies as described earlier. Define the average and minimum prices for online retailers in week $t$ as $\bar{p}_{d t}^{\text {online }}$ and $p_{d t}^{\text {online,min }}$.

We now define several alternative measures of potential savings. The first measure is the savings a naive (or nonsearching, or uninformed) consumer could obtain. A naive consumer is defined as one who purchases randomly with equal probabilities across cards. For a single purchase of the drug at a given point in time, if this consumer uses a card instead of buying at the regular wholesale price (i.e., outside the discount program), the savings are the percentage difference between the average regular price and the average card price. We report the average of these savings across all weeks in the data in percentage form as follows:

$$
S_{d}^{\text {naive }}=\frac{100}{T} \sum_{t=1}^{T}\left(\frac{\bar{p}_{d}^{\text {Mosby }}-\bar{p}_{d t}}{\bar{P}_{d}^{\text {Mosby }}}\right) .
$$

The second measure is the savings that accrued to an Internet searcher, who uses the program website to search for the lowest-price card for a given drug, but otherwise would purchase randomly in the regular market (outside the program) because of higher search costs (as opposed to searching for discounted prices online). The savings of such a consumer are defined as the percentage difference between the average price in the regular market and the minimum price in the discount card market averaged across weeks, and are obtained simply by replacing $\bar{p}_{d t}$ in equation (4) by $p_{d t}^{\min }$.

The third measure we consider is the savings an expert consumer could obtain. An expert con- sumer is defined as one who is fully informed of prices in both markets and thus is always able to purchase at the minimum price. The average savings across weeks for such a consumer are formally defined as the percentage difference between the minimum price in the regular market and the minimum price in the discount card market averaged across weeks, and are obtained by replacing $\bar{p}_{d}^{\text {Mosby }}$ in equation (4) by $p_{d}^{\text {Mosby, min }}$ and $\bar{p}_{d t}$ by $p_{d t}^{\min }$.

Following Baye, Morgan, and Scholten (2003), we also define the "value of information" in the drug discount card market, which is the saving of a consumer informed of all card prices with respect to that of a naive consumer,

$$
V_{d}^{\text {card }}=\frac{100}{T} \sum_{t=1}^{T}\left(\frac{\bar{p}_{d t}-p_{d}^{\min }}{\bar{p}_{d t}}\right) .
$$

We also report the value of information for online prices and prices from Mosby's database.

The defined savings measures and the values of information are reported by drug in Table 4. A naive consumer could obtain an average savings of 11.2 percent. The average savings were even higher for a searcher-about 25 percent. An expert consumer, on the other hand, had little to gain from purchasing in the discount card market: An average savings of only 2.3 percent accrued to such a consumer. Because most drug card users were likely non-experts in searching, the estimate of savings to naive consumers, or at best to searchers, is likely to be the most reasonable estimate.

A somewhat different picture emerges when we consider the savings with respect to online prices. A searcher could obtain an average savings of 8.7 percent by purchasing at the minimum card price instead of purchasing randomly from one of the online pharmacies. However, the benefit for a naive consumer was negative (but statistically insignificant), and an expert consumer could obtain positive (again statistically insignificant) savings. Thus, compared with online prices, card prices did not appear to provide substantial savings. The average value of information also was the highest for regular prices, indicating the biggest rewards to searching, with an average savings for an informed consumer that amounted to around 20 percent of the average price. These savings were 


\section{Dinlersoz, Hernández-Murillo, Li, Sherman}

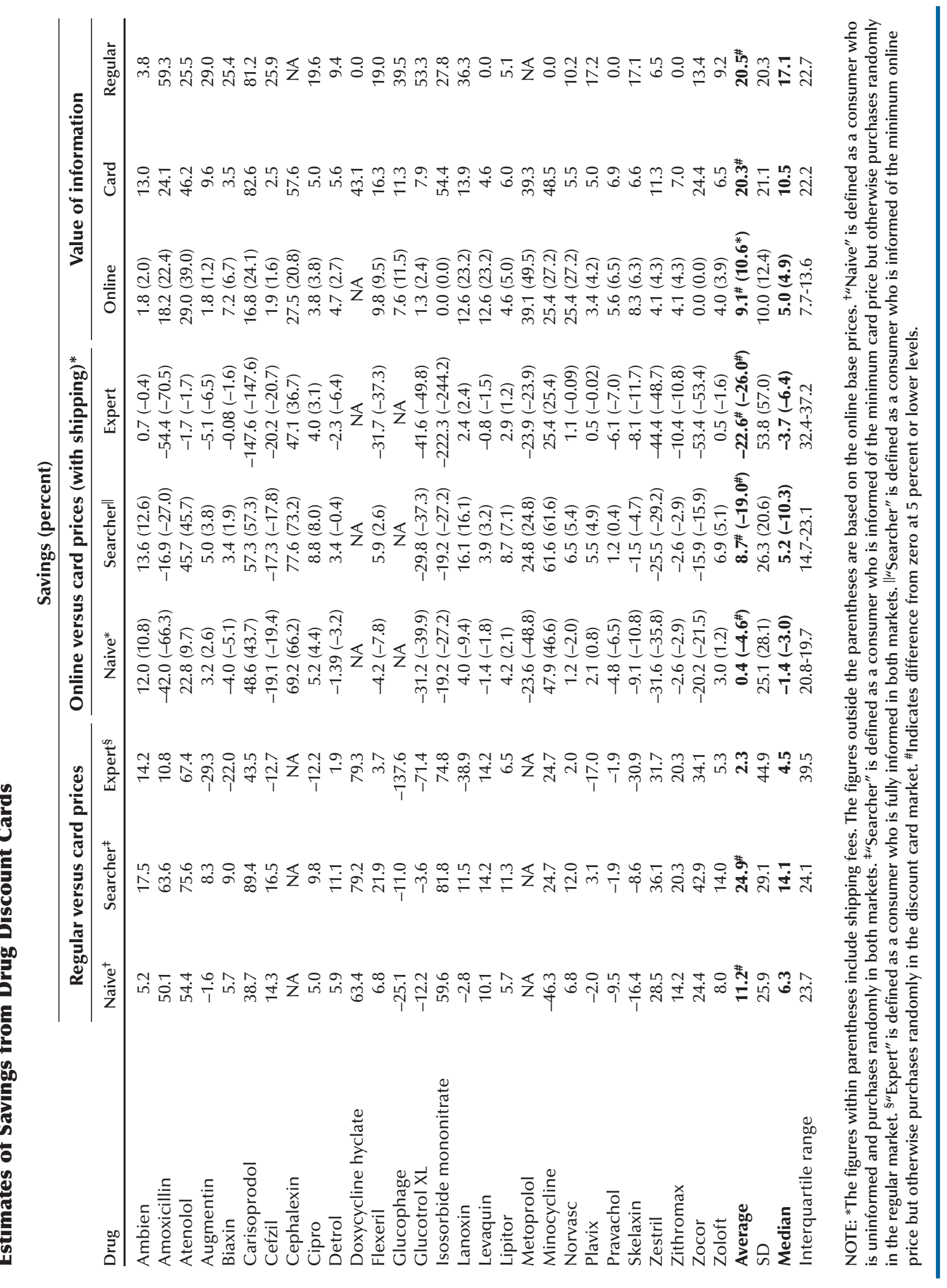


followed closely by card prices. The value of information in the online market was the lowest.

\section{Dynamics of Prices}

We now turn to the evolution of prices. Price changes using two balanced panels of pharmacies from the preswitching period and the postswitching period are examined in the first subsection below. Next, we investigate the behavior of prices around the switching period. The evolution of online prices is examined for comparison with program prices, followed by consideration of the evolution of price dispersion within the program.

\section{Results from the Balanced Panels}

Using a slight modification of equation (1), a price observation can be written as

$$
p_{d r c z t}=\mu+f_{t}+f_{c t}+f_{d t}+f_{d}+f_{c}+f_{r}+f_{z}+\eta_{d r c z t},
$$

where we introduced the interaction terms, $f_{c t}$, a card- and time-specific effect, and $f_{d t}$, a drug- and time-specific effect. The term $f_{c t}$ captures potentially different behavior of cards over time. Different cards may have had different pricing policies that may have depended on time as competition among card sponsors changed. In addition, the time and drug interaction effect, $f_{d t}$, captures the possibility of different drugs experiencing different price changes over time (e.g., cards may have competed more intensely in certain popular drug categories). The fixed effect, $f_{t}$, can be interpreted as the general time effect on prices, which is a combination of the program's effect on price and general fluctuations in drug prices outside the program.

The specification in equation (6) can be estimated using our unbalanced panel of observations. This approach has two drawbacks. First, a very large number of effects (both pure and interaction effects) must be estimated. Second, and more importantly, the included effects are not guaranteed to exhaust the set of relevant effects, which may lead to omitted variable bias, and the timeinvariant fixed effects can potentially be correlated with the error term. One approach to alleviate these concerns is to use time differencing, which eliminates the time-invariant fixed effects. By taking the difference of the prices for two consecutive time periods, $t$ and $t^{\prime}$, we obtain

$$
\Delta p_{d r c z t}=d_{c t}+d_{d t}+d_{t}+\varepsilon_{d r c z t},
$$

where $d_{c t}, d_{d t}$, and $d_{t}$ are the obvious time differences for the corresponding fixed effects and $\varepsilon_{d r c z t}=\left(\varepsilon_{d r c z t}-\varepsilon_{d r c z t}\right)$. Because differencing works only if we have the same pharmacies across the two time periods, we restrict attention to a balanced panel.

Now, consider the following ordinary least squares (OLS) regression based on equation (6):

$$
\Delta p_{d r c z t}=\beta_{c t} D_{c t}+\beta_{d t} D_{d t}+\beta_{t} D_{t}+\varepsilon_{d r c z t},
$$

where $D_{c t}, D_{d t}$, and $D_{t}$ are dummies for the differenced effects $d_{c t}, d_{d t}$, and $d_{t}$. The error term $\varepsilon_{d r c z t}$ has serial correlation, which we take into account in estimating the standard errors.

One problem with this approach is that the balanced panel has a low cross-sectional dimension if we restrict attention only to observations common across all weeks of data in the sample period. Because of errors in accessing the MDDCP website that occurred randomly during the data collection, there was some attrition in our sample and the balanced panel that can be constructed across all weeks of observation is limited in size. However, because this attrition was entirely random, a systematic bias is not a concern. Consequently, we implement regression (8) separately for the seven weeks in the preswitching period and then for the nine weeks in the postswitching period. This approach provides a large, but different, number of cross-sectional observations for both periods. We handle the data for the switching period separately as discussed below.

We first consider the evolution of prices using a panel from weeks 4 to 10 of the program, the preswitching period. The results of the difference regression for this period are shown on the left side of Table 5 . The estimates of $\beta_{t}$ are all negative and statistically significant, except for week 5 of the program. Most of the drop in prices in this period took place between the fifth and eighth weeks, resulting in a decline in general level of prices of about $\$ 4.77$. By the end of the 10th week, the prices were lower by about $\$ 4.63$. However, this 
Table 5

Estimated Coefficients of Time Dummies from the Difference Regressions

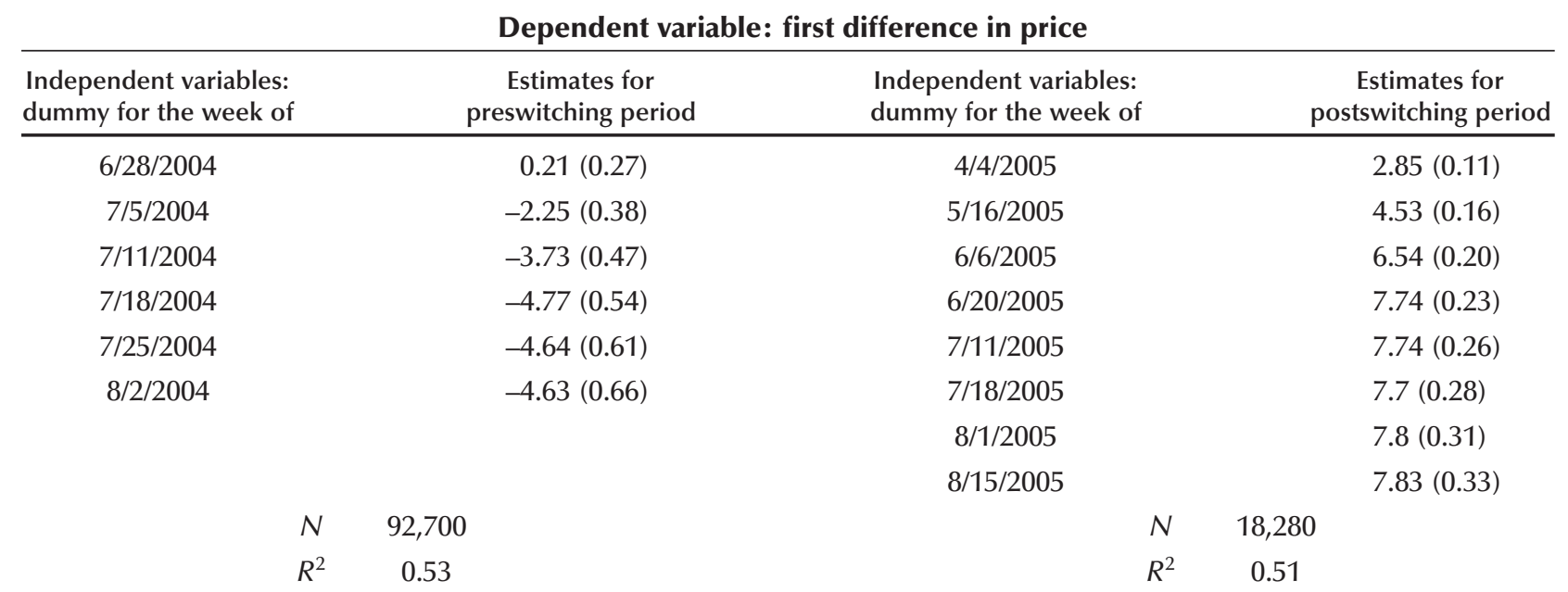

NOTE: Robust standard errors are shown in parentheses. Omitted time dummy is the first week for each regression: 6/21/2004 for the preswitching period and 3/7/2005 for the postswitching period.

reduction represents a small portion (5.5 percent) of the average (\$81.90) of all price observations during the fourth week of the program when data collection began.

We repeated the analysis for the postswitching period using a balanced panel. The evolution of the prices in the sample of weeks from the postswitching period shows a different pattern compared with the preswitching period, as seen on the right side of Table 5 . In fact, the estimated $\beta_{t}$ coefficients are all positive and statistically significant. Between the starting and ending weeks of the sample in the postswitching period, prices rose by about $\$ 8$, controlling for drug and card effects. Much of this increase took place between the end of the switching period and the end of June 2005. Thereafter, prices stabilized somewhat. Between the end of the switching period and the end of June, prices rose at a pace of about $\$ 2$ a month. The total rise in prices represents about 9.5 percent of the average drug price in the fourth week of the program.

Figure 3 displays the discrepancy in the average evolution of prices for different cards and drugs. Specifically, the upper two histograms display the frequency distributions of the time average of the card-time effects plus the puretime effects,

$$
\overline{\hat{\beta}}_{c}=\frac{1}{T} \sum_{t=1}^{T}\left(\hat{\beta}_{t}+\hat{\beta}_{c t}\right)
$$

for the preswitching and postswitching periods, on the left and the right panels, respectively. Analogously, the bottom two panels contain the frequency distributions of the time average, of the drug-time plus the pure-time effects,

$$
\overline{\hat{\beta}}_{d}=\frac{1}{T} \sum_{t=1}^{T}\left(\hat{\beta}_{t}+\hat{\beta}_{d t}\right)
$$

for the preswitching period on the left and the postswitching period on the right. As is evident from the histograms on the left-hand side of the upper and lower panels, most cards and drugs had lower prices during the preswitching period. However, the right tails of these histograms show a few outlier cards and drugs that exhibited an average upward trend in prices even during this period. In contrast, for the postswitching period, all cards and drugs exhibited an average upward 


\section{Figure 3}

\section{Frequency Distribution of Average Card-Time and Drug-Time Effects}

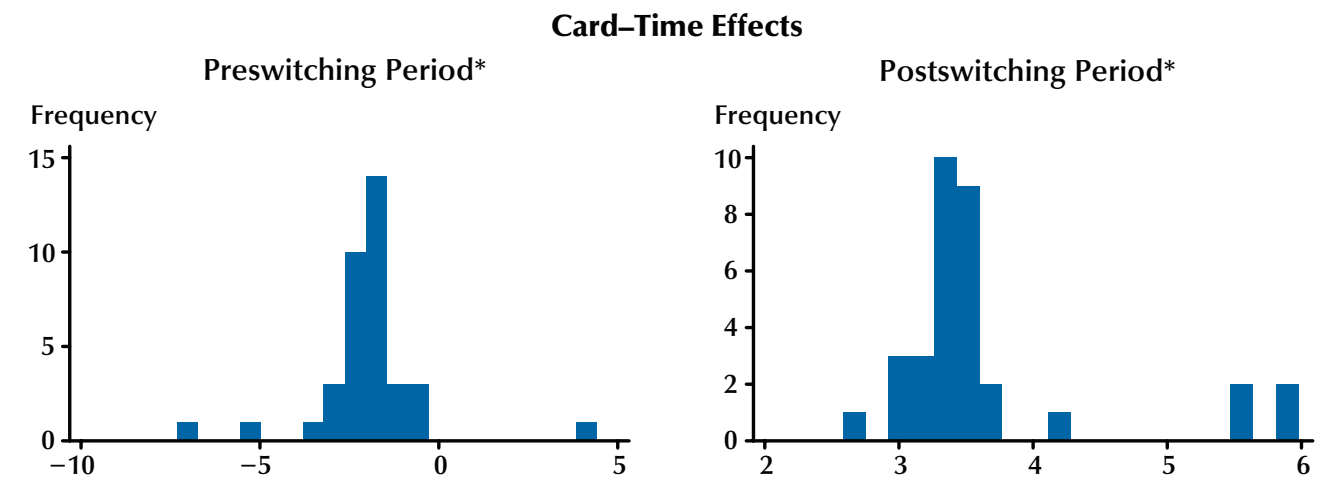

Drug-Time Effects

Preswitching Period**

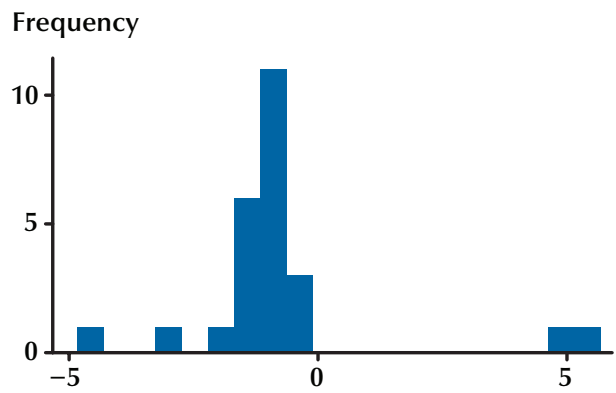

Postswitching Period**

Frequency

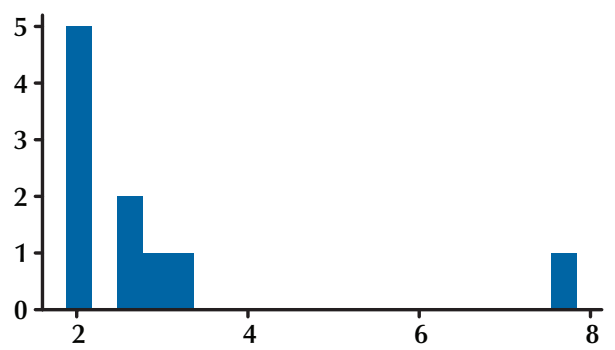

NOTE: *As defined in equation (9). ${ }^{* *}$ As defined in equation (10).

trend in price (seen in the histograms on the right-hand side of the upper and lower panels). Overall, these histograms suggest that prices of cards and drugs on average moved in the same direction within the preswitching and postswitching periods with few exceptions.

We repeated the estimation in equation (8) by adding a long-term drug dummy interaction with a time dummy to explore whether long-term drugs exhibited any different behavior compared with short-term drugs. We found that during the preswitching period, the prices for long-term drugs actually fell less, and during the postswitching period they rose less compared with shortterm drugs. This pattern does not support the hypothesis that consumers searched more vigorously for bargains on these drugs. If this were the case, we would have expected to see a steeper decline for these prices compared with the prices of short-term drugs. ${ }^{15}$

\section{The Switching Period}

For the nationally coordinated card-switching period between November 15 and December 31, 2004, we were able to collect only one week of price data because of technical problems in accessing the website during much of that period. As a result, we were able to collect data for only 15 drugs, and the generally smaller number of observations for that period precluded us from including the switching period in the balanced

\footnotetext{
${ }^{15}$ One possible explanation is that consumers with an existing prescription for a given long-term drug who have purchased from their preferred pharmacy for a long time may not have found it worthwhile to search vigorously for a card and a possibly different pharmacy - which illustrates another form of switching costs.
} 
Table 6

Analysis of Price Changes Around the Switching Period

\begin{tabular}{|c|c|c|c|c|c|c|}
\hline \multirow[b]{2}{*}{ Drug } & \multicolumn{3}{|c|}{$\begin{array}{l}\text { (Switching period price) - } \\
\text { (Preswitching period price) }\end{array}$} & \multicolumn{3}{|c|}{$\begin{array}{l}\text { (Postswitching period price) - } \\
\text { (Switching period price) }\end{array}$} \\
\hline & $\begin{array}{c}\text { Average } \\
\text { difference }(\$)\end{array}$ & Paired $t$ statistic & $p$ Value & $\begin{array}{c}\text { Average } \\
\text { difference (\$) }\end{array}$ & Paired $t$ statistic & $p$ Value \\
\hline Ambien & -1.99 & -6.91 & 0.00 & 0.31 & 5.42 & 0.00 \\
\hline Amoxicillin & -2.28 & -26.56 & 0.00 & 1.33 & 11.38 & 0.00 \\
\hline Atenolol & -0.77 & -9.62 & 0.00 & 0.18 & 0.67 & 0.49 \\
\hline Augmentin & -3.07 & -2.46 & 0.01 & 0.72 & 2.88 & 0.00 \\
\hline Biaxin & -2.65 & -10.55 & 0.00 & 2.80 & 22.66 & 0.00 \\
\hline Carisoprodol & -0.63 & -1.29 & 0.04 & 1.50 & 3.29 & 0.00 \\
\hline Cefzil & -2.93 & -17.94 & 0.00 & -0.10 & -0.89 & 0.37 \\
\hline Cipro & -4.81 & $-\mathbf{5 . 0 0}$ & 0.00 & 3.69 & 3.35 & 0.00 \\
\hline Detrol & -2.09 & -4.18 & 0.00 & 3.27 & 12.47 & 0.00 \\
\hline Doxycycline hyclate & 0.58 & 8.73 & 0.00 & 0.21 & 4.25 & 0.00 \\
\hline Flexeril & -0.70 & -3.18 & 0.00 & 2.61 & 16.08 & 0.00 \\
\hline Glucotrol XL & 0.34 & 7.92 & 0.00 & 1.03 & 14.00 & 0.00 \\
\hline Isosorbide mononitrate & -3.36 & -14.22 & 0.00 & 2.30 & 1.31 & 0.18 \\
\hline Lanoxin & 1.32 & 22.87 & 0.00 & 0.05 & 0.60 & 0.54 \\
\hline Levaquin & -3.80 & -10.78 & 0.00 & 2.48 & 12.42 & 0.00 \\
\hline Average & -1.79 & & & 1.49 & & \\
\hline Standard error & 0.45 & & & 0.33 & & \\
\hline
\end{tabular}

NOTE: "Switching period price" is the price during the one week of data available from the switching period. "Preswitching period price" is the price during the last week (week of 8/2/2004) of price observations in our preswitching period sample. "Postswitching period price" is the price during the first week (week of 4/4/2005) of price observations in our postswitching period sample. Bold $t$ statistics indicate significance at 5 percent or lower levels.

panel analysis of the previous section. Instead, we compared the average price level for each drug using two paired $t$ tests. For each drug, we perform two paired $t$ tests across common cards and pharmacies: one for the difference between the week from the switching period and the last week of the preswitching period, and the other for the difference between the first week of the post switching period and the week from the switching period. The paired $t$ test approach eliminates the fixed effects that are common across the two periods and isolates the time effects, just like the balanced panel used previously.

As shown in Table 6, both tests indicated a statistically significant decline in prices for most drugs (12 of 15) between the last week of the pre - switching period and the week of the switching period, and a subsequent statistically significant rise for most drugs (11 of 15) between the week of the switching period and the first week of the postswitching period. The magnitude of price drops and raises varied across drugs. Overall, prices declined on average by about $\$ 1.80$ between the week of August 2, 2004, and the week of December 20, 2004, and rose on average by about $\$ 1.50$ between the week of December 20, 2004, and March 7, 2005.

Given the nature of the timing of data collection, we cannot say precisely whether the decline in prices between the week of August 2, 2004, and the week of December 20, 2004, was confined to the switching period only. Because card enroll- 
ment continued during this period, card sponsors could have continued to reduce their prices to some extent to attract additional consumers, as they did in the initial phases of the program. Some card sponsors, in anticipation of the switching period, may have also lowered prices in an effort to deter consumers from switching. Thus, some of the observed price decline in this period could have occurred even before the switching period. We are more comfortable attributing the rise in prices after the switching period to the existence of switching costs, because during that period card enrollment diffused to a large extent and enrolled consumers were committed until the end of the program.

In summary, the evidence from the balanced panel estimation and the paired $t$ tests points to initially declining but later rising prices, even though the magnitudes of change in price levels were not exceptionally large compared with the average price level across drugs. The pattern exhibited by prices lends more support to a model in which prices move in a nonmonotonic path, falling when consumers could switch cards and rising when they could not switch cards.

\section{Evolution of Nonprogram Online Prices}

We now consider the evolution of online drug prices as a benchmark for the evolution of program prices. If the time effects found in the evolution of program prices are specific to the program rather than being driven entirely by general trends in drug prices, the same time effects should not emerge for online prices unrelated to the program. To explore this possibility we consider a regression of the form

$$
p_{d i t}=\alpha+\beta_{t} D_{t}+\beta_{i} D_{i}+\beta_{d} D_{d}+\varepsilon_{d i t}
$$

where $D_{t}$ is a time dummy, $D_{i}$ is a dummy for online retailer $i$, and $D_{d}$ is a dummy for drug $d$. The focus is once again on the estimates of the coefficients of time dummies.

Few problems were encountered in data collection of online prices over time, so our sample includes a larger number of weeks and the price changes can be observed with a higher frequency over a longer period, sometimes even more fre- quently than once a week. Table 7 presents the results of the estimation in equation (11). The time dummies have almost uniformly positive and significant coefficients, and the coefficients are almost monotonically increasing over time. By the last week of data, prices were higher by about $\$ 3.39$, controlling for vendor and drug fixed effects.

We repeated the estimation in equation (11) using the total price (base price plus shipping fee) as the dependent variable and the results were very similar. The total price increased over time by about $\$ 3.53$ and the estimated coefficients were uniformly positive and statistically significant in almost all cases.

Finally, we also used a balanced panel approach as in equation (8) to estimate the time effects for online prices. The size of this panel was much smaller than that of the unbalanced panel used in equation (11), because we did not have prices for all sellers and for all drugs every week. The average growth rate of price between the first and the last periods of observation was 3.31 percent (SD 0.11 percent). Only four drugs exhibited a decline in price. Overall, the results from the balanced panel were similar qualitatively to the estimates of time dummy coefficients in Table 7.

The observed pattern for online drug prices thus indicates that the evolution of program prices was indeed different from the evolution of prices outside the program. Online prices tended to rise over time, in contrast to the program prices, which first declined and later increased. Because online prices are subject to general trends in drug prices, but not to the effects of the program, the patterns suggest that the evolution of program prices is at least in part driven by program effects, rather than entirely by general trends. First, online prices rose during the preswitching period when the program prices exhibited a clear decline. The decline in program prices is consistent with the predictions of dynamic price competition models, suggesting an escalated competition in the early stages of a market when sellers lower their prices to lure consumers. Second, the overall rise in online prices fell short of the rise in program prices during the postswitching period. 
Table 7

Estimated Time Dummies for Online Price Regression

\begin{tabular}{|c|c|c|c|c|c|}
\hline \multirow{2}{*}{$\begin{array}{c}\begin{array}{c}\text { Independent } \\
\text { variables }\end{array} \\
\text { Dummy for the date: }\end{array}$} & \multicolumn{2}{|c|}{$\begin{array}{c}\text { Dependent } \\
\text { variable }\end{array}$} & \multirow{2}{*}{$\begin{array}{c}\begin{array}{c}\text { Independent } \\
\text { variables }\end{array} \\
\text { Dummy for the date: }\end{array}$} & \multicolumn{2}{|c|}{$\begin{array}{l}\text { Dependent } \\
\text { variable }\end{array}$} \\
\hline & Base price & Total price & & Base price & Total price \\
\hline Preswitching period & & & Postswitching period & & \\
\hline $6 / 28 / 2004$ & $0.00(0.58)$ & $0.00(0.58)$ & $1 / 13 / 2005$ & $1.95(0.63)$ & $1.99(0.63)$ \\
\hline $7 / 8 / 2004$ & $0.00(0.58)$ & $0.00(0.58)$ & $5 / 6 / 2005$ & $2.62(0.62)$ & $2.66(0.62)$ \\
\hline $7 / 15 / 2004$ & $0.00(0.58)$ & $0.00(0.58)$ & $5 / 27 / 2005$ & $2.81(0.62)$ & $2.85(0.62)$ \\
\hline $7 / 26 / 2004$ & $1.73(0.60)$ & $1.74(0.60)$ & $6 / 10 / 2005$ & $2.81(0.62)$ & $2.85(0.62)$ \\
\hline 8/3/2004 & $1.73(0.60)$ & $1.74(0.60)$ & $6 / 20 / 2005$ & $2.81(0.62)$ & $2.85(0.62)$ \\
\hline $8 / 10 / 2004$ & $1.73(0.60)$ & $1.74(0.60)$ & $7 / 11 / 2005$ & $3.25(0.62)$ & $3.31(0.62)$ \\
\hline $8 / 17 / 2004$ & $1.73(0.60)$ & $1.74(0.60)$ & $7 / 29 / 2005$ & $3.25(0.62)$ & $3.31(0.62)$ \\
\hline $8 / 24 / 2004$ & $1.73(0.60)$ & $1.74(0.60)$ & 8/1/2005 & $3.30(0.62)$ & $3.36(0.62)$ \\
\hline 9/1/2004 & $1.81(0.61)$ & $1.87(0.61)$ & 8/18/2005 & $3.33(0.66)$ & $3.38(0.66)$ \\
\hline $9 / 13 / 2004$ & $1.82(0.62)$ & $1.87(0.62)$ & 9/16/2005 & $3.39(0.66)$ & $3.53(0.66)$ \\
\hline 9/15/2004 & $1.83(0.61)$ & $1.85(0.61)$ & $9 / 29 / 2005$ & $3.39(0.66)$ & $3.53(0.66)$ \\
\hline $9 / 21 / 2004$ & $1.86(0.60)$ & $1.91(0.61)$ & $10 / 4 / 2005$ & $3.39(0.66)$ & $3.53(0.66)$ \\
\hline $9 / 24 / 2004$ & $1.86(0.60)$ & $1.91(0.61)$ & 10/16/2005 & $3.39(0.66)$ & $3.53(0.66)$ \\
\hline $9 / 28 / 2004$ & $1.86(0.60)$ & $1.91(0.61)$ & $10 / 17 / 2005$ & $3.39(0.66)$ & $3.53(0.66)$ \\
\hline $10 / 5 / 2004$ & $1.81(0.63)$ & $1.85(0.63)$ & $10 / 20 / 2005$ & $3.39(0.66)$ & $3.53(0.66)$ \\
\hline $10 / 15 / 2004$ & $1.88(0.63)$ & $1.89(0.64)$ & & & \\
\hline $10 / 20 / 2004$ & $1.55(0.64)$ & $1.56(0.64)$ & & & \\
\hline \multicolumn{6}{|l|}{ Switching period } \\
\hline $12 / 10 / 2004$ & $1.93(0.62)$ & $1.97(0.62)$ & & & \\
\hline $12 / 29 / 2004$ & $1.89(0.62)$ & $1.93(0.62)$ & & & \\
\hline$N$ & 2,955 & & & & \\
\hline$R^{2}$ & 0.98 & & & & \\
\hline
\end{tabular}

NOTE: Robust standard errors are shown in parentheses. Total price includes shipping fee for standard delivery for each vendor. Dates refer to the day the price data were collected. Preswitching period: before 12/2004; switching period: 12/2004; postswitching period: after $12 / 2004$.

Indeed, the program prices actually increased about $\$ 4$ more than online prices by the end of this period. Therefore, the upward trend in program prices after the switching period cannot be explained simply by a general rise in drug prices caused by nonprogram effects.

In addition to the evolution of levels of prices, we also investigated the evolution of price dispersion. To measure price dispersion at any point in time, we first calculated the average of a drug's price within a card. Next, we computed the dis- persion of that average around its mean across cards. We then used the balanced panel of observations to test the hypothesis that the price dispersion remained the same over time versus the alternative that dispersion changed. We found no overwhelming evidence that the dispersion of average price across cards changed substantially during the preswitching or the postswitching periods. The dispersion of prices was persistent over the course of the program. 


\section{CONCLUSION}

We used a large panel of drug prices to assess the effects of government-sponsored release of price information over the Internet under the MDDCP. The designers of the program began with the premise that access to price information by consumers would lower prices over time. In contrast, the card prices and their dispersion did not steadily decline over time, as some models of improved access to price information suggest. Instead, prices declined during the initial phases of the program but then increased later when consumers were unable to switch cards. The evolution of program prices exhibited significant deviation from the general evolution of prices outside the program.

The nonmonotonic evolution of program prices can be reconciled with the predictions of certain models of dynamic price competition with consumer switching costs, such as that of Klemperer (1987). The very design of the program left consumers vulnerable to price changes by card sponsors. Card sponsors appeared to have reduced their prices initially, possibly in an effort to lure customers to subscribe, but then raised their prices in the later stages of the program to take advantage of consumers when they were locked in to their choices. However, we are unable to provide any direct evidence on the actual subscription patterns by card or whether consumers switched cards at all.

The extent to which these patterns will carry over to Medicare's Part D prescription drug assistance program currently in effect remains to be seen. Although Part D has a much more complicated structure, some drivers of price dynamics under MDDCP also apply to Part D. For instance, consumers can switch plans only from November 15 through December 31 of every year, except in special cases. There are also certain differences between the two programs. Consumer non-enrollment in Part D carries a financial penalty that becomes gradually more severe, unlike in the case of the MDDCP, where enrollment was voluntary. Also, the prescription drug benefit providers engage in a multiperiod, long-horizon competition under Part D, instead of the twoperiod interaction under the MDDCP. This broader time horizon introduces considerations of market growth. Thus, prescription drug benefit providers will set prices for a broader horizon, probably considering the trade-off between charging lower prices to attract newcomers and higher prices to already committed consumers. The differences between the two programs notwithstanding, the evidence from the MDDCP does not straightforwardly suggest a secular decline in the level and the dispersion of prices under Part D.

\section{REFERENCES}

Antos, Joseph and Pinell, Ximena. Private Discounts, Public Subsidies: How the Medicare Prescription Drug Discount Card Really Works. Washington, DC: AEI Press, 2004.

Baye, Michael; Morgan, John and Scholten, Patrick. "The Value of Information in Online Markets: Theory and Evidence." Journal of Public Policy and Marketing, Spring 2003, 22(1), pp. 17-25.

Brown, Jeffrey and Goolsbee, Austan. "Does the Internet Make Markets More Competitive? Evidence from the Life Insurance Industry." Journal of Political Economy, June 2002, 110(3), pp. 481-507.

Burdett, Kenneth and Judd, Kenneth. "Equilibrium Price Dispersion.” Econometrica, July 1983, 51(4), pp. 955-69.

Farrell, Joseph and Shapiro, Carl. "Dynamic Competition with Switching Costs.” Rand Journal of Economics, Spring 1988, 19(1), pp. 123-37.

Fox, Susannah. Older Americans and the Internet. Washington, DC: Pew Internet and American Life Project, 2004.

Greene, William H. Econometric Analysis. Second Edition. New York, NY: Macmillan, 1993.

Hassol, Andrea; Jureidini, Susan; Doksum, Teresa and Hadden, Louise. "Evaluation of the MedicareApproved Prescription Drug Discount Card and Transitional Assistance Program.” Final Report Prepared for Centers for Medicare and Medicaid Services. Cambridge, MA: Abt Associates, Inc., 2005. 
Heiss, Florian; McFadden, Daniel and Winter, Joachim. "Who Failed to Enroll in Medicare Part D, and Why? Early Results." Health Affairs, September/ October 2006, 25(5), pp. w344-w354.

Klemperer, Paul. "Markets with Consumer Switching Costs.” Quarterly Journal of Economics, May 1987, 102(2), pp. 375-94.

Mosby's Drug Consult. 14th Edition. St. Louis, MO: Mosby Elsevier, 2004.

Mosby’s Drug Consult. 15th Edition. St. Louis, MO: Mosby Elsevier, 2005

Reinganum, Jennifer. "A Simple Model of Equilibrium Price Dispersion.” Journal of Political Economy, August 1979, 87(4), pp. 851-58.

Salop, Steve and Stiglitz, Joseph. "Bargains and Ripoffs: A Model of Monopolistically Competitive Prices." Review of Economic Studies, October, 1977, 44(3), pp. 493-510.

Sorensen, Alan T. "Equilibrium Price Dispersion in Retail Markets for Prescription Drugs.” Journal of Political Economy, August 2000, 108(4), pp. 833-50.

Sorensen, Alan T. "Price Dispersion and Heterogeneous Consumer Search for Retail Prescription Drugs." NBER Working Paper No. 8548, National Bureau of Economic Research, 2001.
Scott-Morton, Fiona M. "The Interaction Between a Most-Favored-Customer Clause and Price Dispersion: An Empirical Examination of the Medicaid Rebate Rules of 1990." Journal of Economics and Management Strategy, March 1997, 6(1), pp. 151-74.

Stahl, Dale O. "Oligopolistic Pricing with Sequential Consumer Search.” The American Economic Review, September 1989, 79(4), pp. 700-12.

Stahl, Dale O. "Oligopolistic Pricing and Advertising." Journal of Economic Theory, October 1994, 64(1), pp. 162-77.

U.S. Government Accountability Office. "Drug Card Education and Outreach.” Report GAO-06-139R. November 18, 2005.

U.S. Census Bureau. Census 2000 Summary Files. Accessed August 2005; http://factfinder.census.gov.

Winter, Joachim; Balza, Rowilma; Caro, Frank; Heiss, Florian; Jun, Byung-hill; Matzkin, Rosa and McFadden, Daniel. "Medicare Prescription Drug Coverage: Consumer Information and Preferences." Proceedings of the National Academy of the Sciences, May 2006, 103(20), pp. 7929-34. 